\title{
Evidence of circulating donor genetic material in bone allotransplantation
}

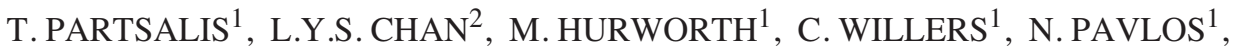

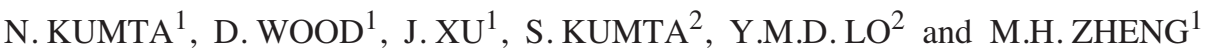 \\ ${ }^{1}$ Department of Orthopaedic Surgery, School of Surgery and Pathology, University of Western Australia, \\ Nedlands 6009, Perth, WA, Australia; ${ }^{2}$ Department of Chemical Pathology, The Chinese University of \\ Hong Kong, Prince of Wales Hospital, Shatin, Hong Kong SAR, P.R. China
}

Received December 2, 2005; Accepted January 18, 2006

\begin{abstract}
Musculoskeletal allotransplantion is the most common form of human tissue transplantation. Unlike solid organ transplants, bone allotransplants undergo rigorous processing and are considered non-viable tissue. In this study, we propose that donor genetic material may exist in circulation after bone allotransplantation. Fifty-one female patients who received bone allotransplants from male donors were assessed. Blood plasma samples were analyzed using realtime quantitative polymerase chain reaction (PCR) with dual labeled fluorogenic probes for the presence of the $S R Y$ gene on the Y chromosome. Of the total 51 patients, the SRY sequence was detected in 6 patients. Five were positive at day 1 postoperatively and negative thereafter, with the remaining patient positive at 3 months post-transplantation. Our results document, for the first time, the presence of donor DNA in the circulation of recipients after bone allotransplantation. Our findings suggest a potential new investigative tool to assess the postoperative status of bone allotransplants.
\end{abstract}

\section{Introduction}

Musculoskeletal allotransplants (allografts) are by far the most common of all human tissues transplanted after blood transfusion. Demand for these tissues continues to grow unabated, to the degree that shortages and subsequent waiting lists are seen for certain tissues, reflecting their relative safety, ease of use, and increasing requirement. In 2001, tissue banks distributed over 875,000 musculoskeletal allotransplants in the US alone (1). Bone allotransplantations are classically used for major reconstructive surgery following trauma, limb salvage following tumor resection, prosthetic

Correspondence to: Professor M.H. Zheng, Department of Orthopaedic Surgery, School of Surgery and Pathology, University of Western Australia, 2nd Floor, M Block, QE2 Medical Center, Monash Avenue, Nedlands, Perth 6009, Western Australia, Australia

E-mail: zheng@cyllene.uwa.edu.au

Key words: allotransplantation, allograft, $S R Y$ gene joint revision surgery and spinal surgery. In addition, cancellous and milled bone has limitless applications where an osteoinductive or osteo-conductive bone graft is required, as in non-union fracture cases.

The application of bone allotransplantation varies, including filling an osseous defect, assisting with mechanical stability, or reconstructing a joint. However, the ultimate goal is its structural and biological incorporation into the host tissue. This refers to the allotransplant-host interaction which leads to new bone formation with subsequent sound mechanical and structural properties. Complete bone incorporation may take several years, and the precise process remains incompletely understood. Nonetheless, the type of allotransplant, the nature of tissue at the allotransplant-host interface, and the overall health of the host are known to be vital determinants of bone allotransplant incorporation (2). Failure of incorporation presents clinically as either non-union, fracture or infection, and represents a poor patient prognosis often requiring revision surgery and prolonged hospitalization (3-5).

Unlike solid organ transplants, which occur within hours of organ procurement, bone allotransplants undergo rigorous processing, irradiation and freezing prior to storage, often for years, at sub-zero temperatures $\left(-70^{\circ} \mathrm{C}\right)$. This process is thought to render the allotransplant free of antigenic material, thus removing the need for donor-recipient matching. However, although no immune suppression is necessary for recipients of bone allotransplants, immune rejection has been suggested as a possible contributor to bone allotransplant non-incorporation and failure. Indeed, immune reactions have been documented, but with poor correlation to the clinical and functional state of the patient (6-8).

Donor-specific genetic material has been detected in the plasma of patients having received solid organ transplants (9). It is suggested that this donor material is a result of tissue necrosis and cell death, and may thus represent a marker for organ rejection (9). Conversely, the presence of donor DNA has been postulated to reflect a degree of immunomodulation and development of a chimeric state which may enhance graft tolerance (10). Whether a similar phenomenon exists with the use of bone allotransplants has not been established.

In this study, we investigated the possible transfer of cellular material following bone allotransplantation by probing for the presence of donor DNA, specifically the sex-determining 
region of the $\mathrm{Y}$ chromosome (SRY), in recipient blood plasma. We propose that the presence of such material may serve as a potential diagnostic marker of bone allotransplant incorporation, thus opening new avenues for investigating the biological sequelae of bone allotransplantation.

\section{Materials and methods}

Fifty-one female patients who received a bone transplant from male donors were included in this study. Patients were recruited from Perth, Western Australia, and Hong Kong SAR, China. Forty patients who received bone transplantation from the Perth Bone and Tissue Bank registry were identified. Blood samples were taken postoperatively and analyzed between 6 weeks and 18 months from the date of surgery. In addition, 11 patients scheduled to undergo surgery and receive a bone transplant were recruited from the Prince of Wales Hospital, Hong Kong SAR. Blood samples from these patients were taken both preoperatively and at day 1, and 1,2, and 3 months postoperatively. All blood and tissue analyses were performed in Hong Kong.

The study was approved by the Human Ethics Committees of both the University of Western Australia and the Chinese University of Hong Kong. All of the patients involved in the study provided written consent for the procedures described.

All bone transplantations, from both Perth and Hong Kong, were prepared and processed according to guidelines set by the American Association of Tissue Banks and the Council of Europe, thus ensuring consistency of transplanted material $(11,12)$. The donor tissue was screened negative for human immunodeficiency virus (HIV), hepatitis B and C, human Tcell lymphoma virus (HTLV) and microbiological contamination.

Blood samples were analyzed for the presence of the $S R Y$ gene on the Y chromosome, using protocols previously described (16). Briefly, $5 \mathrm{ml}$ of venous blood, collected in tubes containing EDTA, was centrifuged twice at 3,000 x g to separate plasma from blood/buffy coat. The resulting supernatants were collected in fresh polypropylene tubes and stored at $-20^{\circ} \mathrm{C}$. DNA extraction was performed using a QIAamp Blood Kit (Qiagen, Hilden, Germany), according to the manufacturer's protocol. Eight hundred $\mu 1$ plasma was applied to each Qiagen column and $10 \mu \mathrm{l}$ of the final $50 \mu \mathrm{l}$ eluate was subjected to real-time quantitative PCR specific for the $S R Y$ gene. PCR for $\beta$-globin served as a positive control for the amplification.

Real-time quantitative PCR analyses were performed in an Applied Biosystems 7700 Sequence Detector. PCR primers, and complementary dual-labeled fluorogenic hybridization probes, were added ad libitum for all reactions. 6-Carboxyfluoroscein (FAM) served as a reporter, its emission spectrum quenched by 6-carboxy-tetramethylrhodamine (TAMRA). During extension, the Taq polymerase cleaved the reporter from the probe resulting in an increase in fluorescence at $518 \mathrm{~nm}$, measured by the 7700 Sequence Detector. The SRY TaqMan system consisted of the amplification primers $S R Y$ 109F, 5'-TGG CGA TTA AGT CAA ATT CGC-3'; and $S R Y$ 245R, 5'-CCC CCT AGT ACC CTG ACA ATG TAT T-3'; and a dual-labeled fluorescent TaqMan probe, SRY-142T, 5'-(FAM)AGC AGT AGA GCA GTC AGG GAG GCA
GA(TAMRA)-3'. The $\beta$-globin TaqMan system consisted of the amplification primers, $\beta$-globin-354F, 5'-GTG CAC CTG ACT CCT GAG GAG A-3'; and $\beta$-globin-455R, 5'-CCT TGA TAC CAA CCT GCC CAG-3'; and a dual-labeled fluorescent TaqMan probe, $\beta$-globin-402T, 5'-(FAM)AAG GTG AAC GTG GAT GAA GTT GGT GG(TAMRA)-3'. TaqMan probes incorporated a 3'-blocking phosphate group to preclude probe extension during PCR.

PCR reagents (excepting probes/primers) were supplied in the TaqMan PCR Core Reagent Kit (Perkin-Elmer). TaqMan probes were custom-designed by Applied Biosystems. PCR primers were synthesized by Life Technologies (Hong Kong, China). The volume of each amplification reaction was $50 \mu 1$. Reaction mixtures contained: $5 \mu 1$ of $10 \mathrm{X}$ buffer A; $300 \mathrm{nM}$ each primer; $100 \mathrm{nM}$ SRY/ $\beta$-globin TaqMan probe; $4 \mathrm{mM}$ $\mathrm{MgCl}_{2} ; 200 \mu \mathrm{M}$ each of dATP, dCTP, dGTP; $400 \mu \mathrm{M}$ dUTP; 1.25 U AmpliTaq Gold; and 0.5 U AmpErase uracil Nglycosylase for contamination control. DNA amplifications were carried out in 96-well plates; each sample was analysed in duplicate. Duplicated calibration curves were run simultaneously within each plate.

Both $S R Y$ and $\beta$-globin amplification reactions were performed using identical thermal cycles: an initial 2-min incubation at $50^{\circ} \mathrm{C}$ to activate uracil $\mathrm{N}$-glycosylase followed by a primary denaturation step of $10 \mathrm{~min}$ at $95^{\circ} \mathrm{C}$ and, finally, 40 cycles of $95^{\circ} \mathrm{C}$ for $15 \mathrm{sec}$ and $60^{\circ} \mathrm{C}$ for $1 \mathrm{~min}$. Amplification data were processed using the Sequence Detection System software developed by Applied Biosystems, and the concentration of the target was expressed as genome-equivalents $/ \mathrm{ml}$.

All data were analyzed using SPSS for Windows (version 9.0; SPSS, Chicago, IL). Results and values for each subject are presented as means \pm SEM. Differences between patient groups were statistically compared by Student's t-test using SPSS software. Regression analysis was conducted using Microsoft Excel analyses, 2000 edition. All reported p-values were two-tailed and $\mathrm{p}$-values $<0.05$ were considered significant.

\section{Results}

All 51 patients examined were female, with a mean age of 52 years. Of these, 33 patients underwent hip arthroplasty revision surgery, and 18 required spinal surgery, either scoliosis correction (11 patients) or spinal fusion (7 patients). As shown in Table I, the majority (55\%) of implanted bone was milled cortico-cancellous bone used mainly for revision hip arthroplasty, followed by cancellous bone for corrective scoliosis surgery (20\%). The mean age of patients undergoing revision hip arthroplasty was 68 years, patients undergoing spinal fusion had a mean age of 33 years, and scoliosis correction patients were mainly adolescent with a mean age of 14 years (Table II). The mean weight of implanted bone per procedure (Fig. 1) was highest in the scoliosis group $(50 \pm 11.88)$, with a mean $>10$ g greater than revision hip arthroplasty (37.52 \pm 13.99$)$. Spinal fusion had a mean bone implantation weight of $33 \pm 7.94$. No statistical difference was noted between these groups $(\mathrm{p}>0.05)$.

Following bone allotransplantation from a male donor, 6 tested positive for the $S R Y$ sequence. Notably, all $S R Y$ positive patients underwent corrective scoliosis surgery using cancellous bone allotransplantation. Among these patients, 5 
Table I. Type of bone transplant used per surgical procedure.

\begin{tabular}{lccrr}
\hline Bone transplant & $\begin{array}{c}\text { Revision hip } \\
\text { arthroplasty }\end{array}$ & $\begin{array}{c}\text { Spinal } \\
\text { fusion }\end{array}$ & $\begin{array}{c}\text { Scoliosis } \\
\text { correction }\end{array}$ & Total \\
\hline Cancellous bone & 0 & 0 & 10 & 10 \\
Cortical strut graft & 5 & 0 & 1 & 6 \\
Milled cortico-cancellous bone & 22 & 6 & 0 & 28 \\
Combination cortical strut and milled cortico-cancellous bone & 6 & 1 & 0 & 7 \\
Total & 33 & 7 & 11 & 51 \\
\hline
\end{tabular}

Table II. Mean patient age per procedure.

\begin{tabular}{lc}
\hline Procedure & Age (years) \\
\hline Revision arthroplasty & $68.64 \pm 12.86$ \\
Spinal fusion & $33.29 \pm 21.65$ \\
Scoliosis correction & $14 \pm 2.15$ \\
\hline
\end{tabular}

were positive at day 1 postoperatively, and negative thereafter, with 1 positive at 3 months post implantation. Interestingly, this patient had initially tested negative for the $S R Y$ sequence at day 1 , and 1 and 2 months postoperatively. No preoperative blood tests were positive for the $S R Y$ sequence. The number of genome-equivalents of the $S R Y$ gene/ml recipient serum ranged from 2.4 to $275(57.43 \pm 107.27)$. Fig. 2 shows $S R Y$ PCR details for each subject. As seen in Fig. 2, there was no obvious relationship between the total weight of implanted bone and the $S R Y$ gene copies/100 ng bone $\left(\mathrm{R}^{2}=0.11\right)$. In contrast, the total weight of implanted bone and $S R Y$ copies/ $\mathrm{ml}$ recipient serum showed a strong correlation $\left(\mathrm{R}^{2}=0.90\right)$.

\section{Discussion}

In this study, we document the presence of donor DNA in the recipient's circulation after bone allotransplantation. Cell-free DNA was detected despite allograft bone tissue undergoing extensive treatment to render it free of antigenic material. To our knowledge, this is the first reported case of donorrecipient DNA transfer following bone allotransplantation. However, the precise significance of this finding requires further investigation.

Since its discovery in 1948, circulating cell-free DNA has been identified in and associated with various pathological, physiological and iatrogenic conditions $(9,14,15)$. Elevated levels of circulating DNA in both solid organ and hematological malignancies have been described (14). In addition, viral DNA sequences have been detected in the plasma and serum of patients suffering from a wide variety of neoplasms. For example, Epstein-Barr virus (EBV) DNA often exists in the serum of patients suffering nasopharyngeal carcinoma (NPC). Moreover, the concentration of circulating EBV DNA has been shown to correlate with the stage of tumor progression (14). More recently, fetal DNA has been detected in maternal

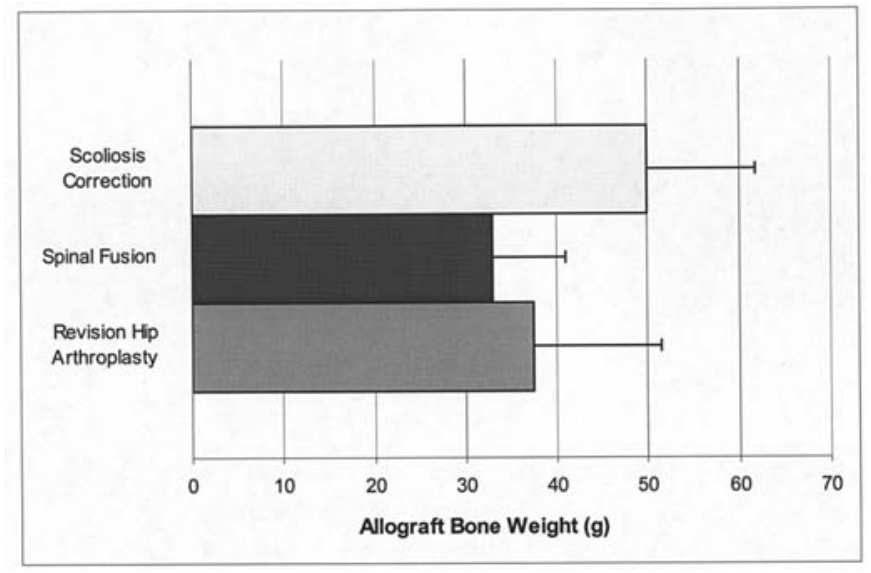

Figure 1. Mean weight of bone transplanted per procedure. Scoliosis correction used the highest mean amount of bone for transplantation over the three procedures assessed, although no statistical difference was seen $(p>0.05)$.

plasma and has been subsequently used in the development of non-invasive prenatal diagnostic tests for high risk pregnancies $(13,15,16)$.

Elevated levels of circulating donor-specific DNA have been observed in patients following liver and kidney transplantation. This increased circulating donor DNA is thought to emanate from dying donor tissue and may thus be a marker for rejection (9). This notion is further supported by studies showing a marked increase in circulating DNA in patients involved in major trauma, with cell death being the presumed source of nucleic acids (17). By contrast, there is evidence to suggest that circulating donor-derived cellular (as opposed to cell-free) DNA in transplant recipients reflects the development of a degree of microchimerism, thereby aiding the acceptance of the transplanted organ (10). It has also been postulated that cellular chimerism may decrease the amount of required immunosuppression after organ transplantation (18). Thus, it appears that cellular and cell-free plasma DNA may represent distinct biological phenomena with possibly diverse biological implications.

Presently, the factors underlying bone allotransplant incorporation into host tissue are incompletely understood. The precise reasons why some transplants incorporate clinically, radiologically, and histologically whilst others fail, leading to non-union, infection, and fracture, remain a subject of debate. Bone preparation and handling is thought to be a 

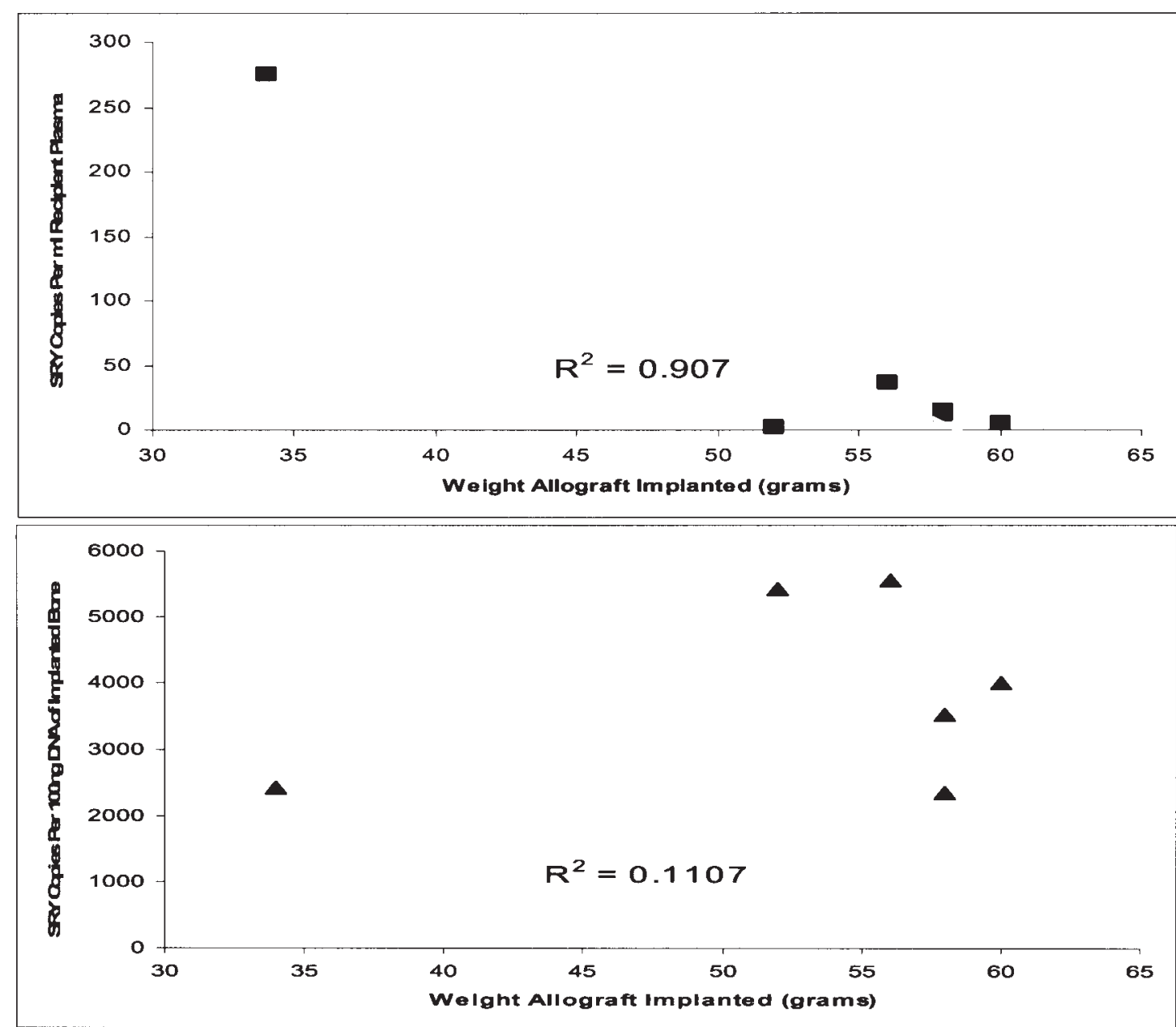

\begin{tabular}{|c|c|c|c|c|}
\hline Patient & Age (years) & $\begin{array}{c}\text { Weight allograft } \\
\text { implanted (grams) }\end{array}$ & $\begin{array}{c}\text { SRY copies per 100 ng } \\
\text { DNA of implanted allograft }\end{array}$ & $\begin{array}{c}\text { SRY copies per ml } \\
\text { recipient's plasma }\end{array}$ \\
\hline 1 & 13 & 34 & 2421 & 275 \\
\hline 2 & 17 & 52 & 5434 & 2.4 \\
\hline 3 & 16 & 56 & 5560 & 36.6 \\
\hline 4 & 11 & 58 & 3531 & 14.4 \\
\hline 5 & 17 & 58 & 2342 & 11.3 \\
\hline 6 & 16 & 60 & 4001 & 4.9 \\
\hline
\end{tabular}

Figure 2. PCR outcomes for $S R Y$-positive patients following bone transplantation for scoliosis correction. No relationship was observed between the total weight of transplanted bone implanted and the $S R Y$ gene genome-equivalents/100 ng transplanted bone (middle), but total weight of transplanted bone implanted and $S R Y$ genome-equivalents $/ \mathrm{ml}$ recipient's serum showed a strong correlation (top).

contributing factor, with studies indicating that irradiated allotransplants exhibit a higher incidence of failure (19). Host physiology is another possibility, with patients undergoing preoperative chemotherapy displaying a higher incidence of allotransplant related complications (7). Finally, surgical factors are an important consideration, with sound mechanical stability of the bone allotransplant and accurate and intimate allotransplant-host contact both known to be essential for incorporation $(2,7)$.

Our findings revealed that 5 of the 6 patients testing positive for donor DNA were positive at day 1 postoperatively and subsequently negative. It is noteworthy that patients testing positive to the $S R Y$ sequence all underwent scoliosis surgery and all had a higher average volume of implanted bone than patients who underwent other procedures. Considering that these patients all received cancellous bone during major spinal surgery, one explanation is that the donor material might have entered the host circulation during intraoperative handling of the bone allotransplant. Alternatively, we cannot exclude the possibility that the dection of the $S R Y$ sequence in these 5 patients was due to intraoperative blood transfusions from male donors. Detection of the $S R Y$ sequence in 1 patient 3 months post-operatively may indicate the possible release of donor material from the bone allotransplant as a result of 
bone remodeling by osteoclastic bone resorption. Although the $S R Y$-positive group was limited to patients undergoing scoliosis correction surgery, regression analysis of SRYpositive cases identified a correlation between the amount of circulating SRY DNA (genome-equivalents $/ \mathrm{ml}$ serum) and the total amount of bone implanted. Thus, this data suggests that the release of donor materials may be associated with the amount of materials implanted.

The inclusion of preoperative blood samples, which were uniformly negative, was an important negative control. This is because previous work has shown that fetal cells may persist in a proportion of women who have previously been pregnant (20). The negativity of the preoperative blood thus excludes the possibility that the observed $S R Y$ signal might be related to pregnancy-associated cellular chimerism.

Although the significance of our findings is limited by the small cohort size and the small number of positive cases, our studies describe a novel phenomenon, with the potential for development of a new diagnostic approach to assess incorporation following bone allotransplantion.

\section{Acknowledgments}

We thank Anne Cowie, Margaret Stone and staff at Perth Bone and Tissue Bank, Hollywood Hospital, Perth, Western Australia. This project was supported by funding from the National Health and Medical Research Council (NHMRC), Australia.

\section{References}

1. Kainer MA, Archibald LK: Clostridium infections associated with musculo-skeletal-tissue transplantations. N Engl J Med 350: 2564-2571, 2004.

2. Bauer TW, Muschler GF: Bone graft materials: an overview of the basic science. Clin Orthop 17: 10-27, 2000.

3. Mankin HJ, Gebhardt MC, Jenning LC, et al: Long-term results of transplantation replacement in the management of bone tumors. Clin Orthop 324: 86-97, 1996.

4. Lord CF, Gebhardt MC, Tomford WW, Mankin HJ, et al: Infection in bone transplantations. Incidence, nature, and treatment. J Bone Joint Surg 70: 369-376, 1988.
5. Dick HM and Strauch RJ: Infection of massive bone transplantations. Clin Orthop 306: 46-53, 1994.

6. Friedlaender GE, Strong DM, Tomford WW and Mankin HJ: Long-term follow-up of patients with osteochondral transplantations. A correlation between immunologic responses and clinical outcomes. Orthop Clin North Am 30: 583-587, 1999.

7. Enneking WF and Campanacci DA: Retrieved human transplantations: a clinicopathological study. J Bone Joint Surg 83: 971-995, 2001.

8. Friedlaender GE: Bone transplantations: the biological consequences of immunological events. J Bone Joint Surg 73: 1119-1122, 1991

9. Lo YMD, Tein MSC, Pang CCP, Yeung CK, et al: Presence of donor specific DNA in plasma of kidney and liver transplant recipients. Lancet 351: 1329-1330, 1998.

10. Starzl TE, Demetris AJ, Murase N, Ildstad S, et al: Cell migration, chimerism and graft tolerance. Lancet 339: 1579-1582, 1992.

11. Guide to the Preparation, Use and Quality Assurance of Blood Components. 10th edition. Council of Europe, 2004.

12. American Association of Tissue Banks: Standards for Tissue Banking, 2001.

13. Lo YMD, Tein MSC, Lau TK, et al: Quantitative analysis of fetal DNA in maternal plasma and serum: implications for noninvasive prenatal diagnosis. Am J Hum Genet 62: 768-775, 1998.

14. Lo YMD, Chan LYS, Lo KW, Leung SF, et al: Quantitative analysis of cell-free Epstein-Barr virus DNA in plasma of patients with nasopharyngeal carcinoma. Cancer Res 59: 1188-1191, 1999.

15. Lo YMD, Corbetta N, Chamberlain PF, Vik R, et al: Presence of fetal DNA in maternal plasma and serum. Lancet 350: 485-488, 1997.

16. Lo YMD, Lau TK, Zhang J, Leung TN, et al: Increased fetal DNA concentrations in the plasma of pregnant women carrying fetuses with trisomy 21. Clin Chem 45: 1747-1751, 1999.

17. Lo YMD, Rainer TH, Chan LY, et al: Plasma DNA as a prognostic marker in trauma patients. Clin Chem 46: 319-323, 2000 .

18. Adams DH and Hutchinson IV: Microchimerism and graft tolerance: cause or effect? Lancet 349: 1336-1338, 1997.

19. Lietman SA, Tomford WW, Gebhardt MC, Springfield DS, Mankin HJ: Complications of irradiated transplantations in orthopaedic tumor surgery. Clin Orthop 375: 214-217, 2000.

20. Bianchi DW, Zickwolf GK, Weil GJ, Sylvester S and De Maria MA: Male fetal progenitor cells persist in maternal blood for as long as 27 years postpartum. Proc Natl Acad Sci USA 93: 705-708, 1996. 